\title{
VOID-CLOSURE BEHAVIOR AND A NEW VOID-EVOLUTION MODEL FOR VARIOUS STRESS STATES
}

\author{
NOV MODEL ZAPIRANJA VOTLIN IN RAZVOJ NOVIH \\ POD VPLIVOM RAZLIČNIH NAPETOSTNIH STANJ
}

\author{
Fei Chen, Xiaodong Zhao, Huiqin Chen*, Jinyu Ren \\ College of Materials Science and Engineering, Taiyuan University of Science and Technology, Taiyuan 030024, P. R. China \\ Prejem rokopisa - received: 2020-07-07; sprejem za objavo - accepted for publication: 2020-10-05
}

doi:10.17222/mit.2020.128

\begin{abstract}
Cavity defects including a shrinkage cavity, air hole and porosity are typical defects of an ingot, which are difficult to avoid. These defects can disappear during deformation at a reasonably high temperature and heat-preservation process so as to ensure the quality of forgings. However the current understanding of the mechanism of the void closure is insufficient, and the models that can accurately predict the evolution of a void are relatively rare. Based on the representative-volume-element model, a theoretical analysis and numerical simulation, the influence of the Lode parameter and stress triaxiality on the void closure is expounded. Besides, based on the above research, a new void-evolution model considering all kinds of macro-stress states is proposed. The model can predict the closure degree of voids in different positions and various macro-stress states during the plastic deformation of ingots. Comparing the new void-evolution model with other models, numerical simulations and physical-simulation results, the accuracy of the proposed void-evolution model is verified.

Keywords: void closure, representative volume element, stress triaxiality, Lode parameter, void-evolution model
\end{abstract}

Kavitacijske napake, nastale zaradi kavitacijskega krčenja, kot so: zračni mehurčki in poroznost, so tipične napake v ingotih, ki se jim v metalurški praksi težko izognemo. Te napake lahko popravimo s pomočjo visokotemperaturne deformacije in s postopkom termične poprave. S tem lahko zagotovimo izdelavo kvalitetnih odkovkov. Vendar pa je današnje razumevanje mehanizmov zapiranja votlin (majhnih praznin v materialu, npr.: pore in lunkerji) nezadostno in so modeli, s katerimi lahko natančno napovemo razvoj votlin, zelo redki. Na osnovi modela volumskega elementa so avtorji razložili mehanizem zapiranja votlin, na osnovi teoretične analize in numerične simulacije, upoštevajoč Lodeov parameter in triosno napetostno stanje. Na osnovi podane raziskave so avtorji poleg tega predlagali nov model razvoja votlin, $\mathrm{z}$ upoštevanjem vseh vrst makronapetostnih stanj. Model lahko napove stopnjo zapiranja praznin na različnih položajih in različna makronapetostna stanja med plastično deformacijo ingotov. Primerjava novega modela razvoja praznin s podobnimi modeli, simulacija in njeni rezultati, so potrdili natančnost njegovih napovedi.

Ključne besede: zapiranje votlin, reprezentativni volumski element, napetostna triosnost, Lodeov parameter, model razvoja votlin

\section{INTRODUCTION}

Cavity defects including a shrinkage cavity, air hole and porosity are typical defects of ingots, which are difficult to avoid, especially in large ingots. ${ }^{1,2}$ These defects need to be eliminated using deformation with a reasonably high temperature and a heat-preservation process to restore the continuity of materials and ensure the quality of forgings. ${ }^{3,4}$

Many scholars carried out a lot of research on the behavior of the void closure and the establishment of a void-closure model. Tanaka et al. considered that the equivalent strain and hydrostatic stress were the important factors affecting the void closure, and proposed parameter $\mathrm{Q}$, which was defined as the integral of the stress triaxiality to equivalent strain to assess the void closure. ${ }^{5,6}$ Nalawade et al. studied the void-closure behavior of a large-section as-cast bar during hot rolling and explored the relationship between parameter $\mathrm{Q}$ and the void closure. ${ }^{7}$ Based on the distribution of the compres-

*Corresponding author's e-mail:

chen_huiqin@126.com (Huiqin Chen) sive-strain field around the void, Chen et al. obtained the quantitative relationship between the void evolution and the compressive strain through a formula derivation and mathematical fitting based on the Gaussian function. ${ }^{8} \mathrm{X}$. $\mathrm{X}$. Zhang et al. ${ }^{9}$ developed a computational program to simulate the void evolution. It could show the change in the relative volume of voids synchronously and intuitively in a simulation of forging of large forgings. N. Harris et al. ${ }^{10}$ analyzed the effects of the far-field equivalent strain, stress triaxiality and material properties on the void closure by studying the void-closure behavior of a large billet forging, and finally proposed a new void-closure model. In order to improve the internal quality of shaft forgings, D. Tian et al. ${ }^{11}$ proposed the floating-pressure method to eliminate the void in an ingot. They investigated the changes in the stress, metal flow and void shape using a numerical simulation, and expounded the mechanism of the floating-pressure method to eliminate the void. ${ }^{11}$ Park conducted an in-depth study on the evolution law of void under a high-stress triaxiality and found that the stress triaxiality and equivalent strain were important factors affecting the 
void closure. With the increase in the stress triaxiality, the void-closure mode changed from collapse to contraction. ${ }^{12}$ Based on the energy principle, S. H. Zhang et al. ${ }^{13}$ established a new criterion for measuring the closure of an ellipsoidal void during thick-plate rolling. The closure behavior of seven kinds of ellipsoidal voids during rolling was simulated with the finite-element method. The new criterion was compared with the results of the finite-element method, and its accuracy was verified. L. Zhang ${ }^{14}$ et al. explored the evolution rule of voids with different shapes, orientations and positions during a stretching process and obtained the critical forging ratio for the void closure of a large billet.

In summary, previous researches on the void-closure behavior required a significant amount of work. However, most of them focused on the evolution behavior of a void with a specific position and shape in an ingot under a specific deformation condition. In recent years, with the development of the finite-element software and the popularity of the representative volume element (RVE), many scholars have begun to analyze the evolution behavior of voids under different stress states based on the RVE model. But this research is still in its infancy. Using the RVE model, the evolution behaviors of voids under complex stress states were analyzed and the characteristic parameters that could quantitatively characterize the void-closure behavior in most stress states were extracted. Based on the characteristic parameters, a new model of the void evolution was established, which comprehensively considers various stress states. A general method was obtained to determine the void evolution in ingots in different positions and different stress states.

\section{REPRESENTATIVE-VOLUME-ELEMENT MODEL AND STRESS BOUNDARY CONDITIONS}

\subsection{Representative-volume-element model}

A RVE model helps us establish the quantitative relationship between the void evolution and macroscopic stress states. ${ }^{15}$ In recent years, many scholars have used RVE models to describe the growth and aggregation of voids under various stress states. ${ }^{16-18}$ A RVE model is shown in Figure 1. The surface of the RVE is subjected to a uniform macroscopic stress. The boundary condition of the RVE is the macroscopic stress state at the marked point on the ingot. No matter how complex the stress state is, it can finally be expressed by the normal stresses on three pairs of mutually perpendicular planes with a zero shear stress. These three pairs of normal stresses are also called principal stresses. By changing the values of the three principal stresses around the RVE model, the stress state around the RVE model can be effectively controlled. In a three-dimensional stress space, the stress state of an infinitesimal can be described with stress tensor $\sigma_{\mathrm{ij}}$ that has nine stress components $\left(\sigma_{\mathrm{x}}, \sigma_{\mathrm{y}}, \sigma_{\mathrm{z}}, \tau_{\mathrm{xy}}, \tau_{\mathrm{yx}}\right.$, $\left.\tau_{\mathrm{yz}}, \tau_{\mathrm{zy}}, \tau_{\mathrm{zx}}, \tau_{\mathrm{xz}}\right)$. The stress tensor can be decomposed into the spherical stress tensor and deviatoric stress tensor. When the coordinate axis and the stress principal axis overlap, the shear stress is 0 and the three normal stresses are called the principal stresses, namely $\sigma_{1}, \sigma_{2}$, $\sigma_{3}$. For the convenience of the following discussion, the principal axes of the stress tensor were required to coincide with the principal axes of the Cartesian coordinate system. Meanwhile, it was postulated that $\sigma_{1}=\sigma_{\mathrm{x}}, \sigma_{2}=$ $\sigma_{\mathrm{y}}, \sigma_{3}=\sigma_{\mathrm{z}}$, and $\sigma_{1} \geq \sigma_{2} \geq \sigma_{3}$.

\subsection{Stress boundary conditions}

The shape of the void in an actual ingot is varied, but in order to obtain the general rule with engineering significance to the actual production and reduce the difficulties of analyzing and calculating, the smallest sphere containing the actual cavity defect can usually be taken as the shape of the void. This increases the volume of the void, but the results are more conservative. Therefore, a spherical void was selected to explore the void-closure behavior.

In this paper, the DEFORM-3D and RVE model were used for the numerical simulation to study the void-closure behavior under different macroscopic stress states. In order to simplify the calculation, the $1 / 8$ RVE model was selected for the simulation. Figure 2 shows the $1 / 8$ RVE model which is a regular hexahedron of $(5 \times 5 \times 5) \mathrm{mm}$. The center of the model contains a spherical void whose

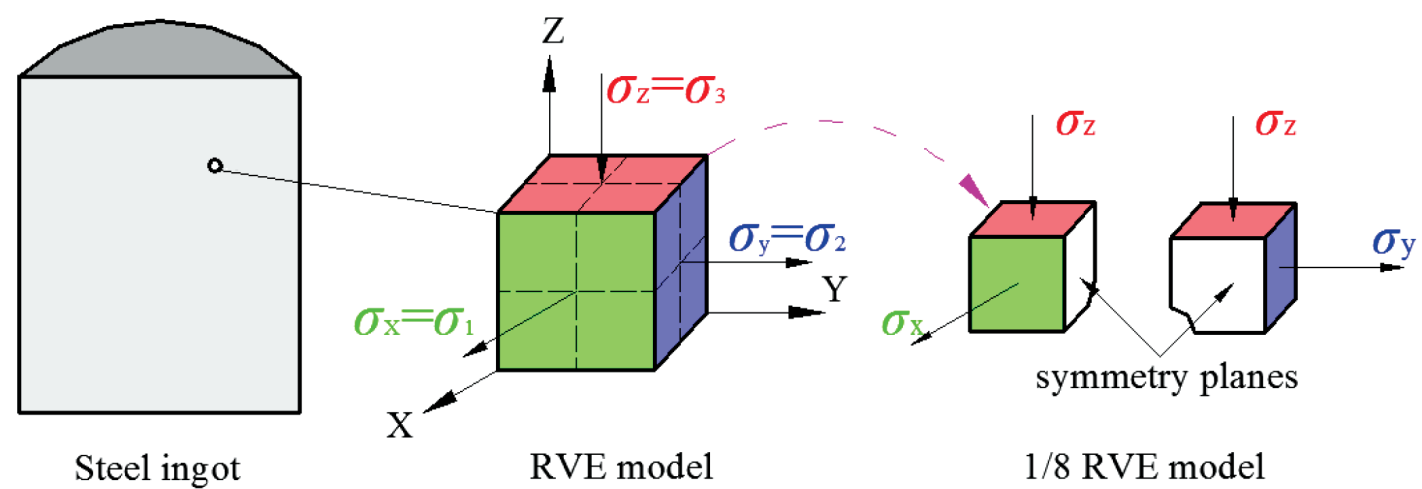

Figure 1: Representative-volume-element model 


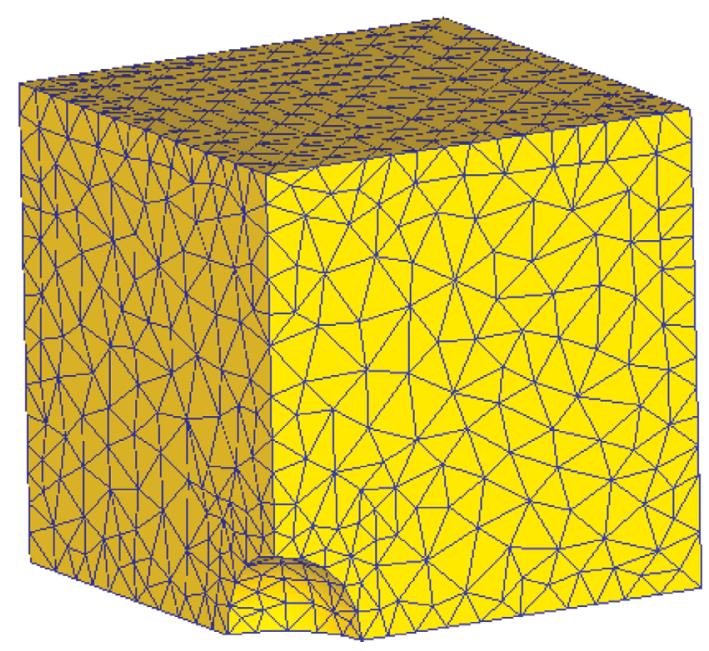

Figure 2: 1/8 RVE model with a void in the center

radius is $1 \mathrm{~mm}$. Besides, $\mathrm{Pb}$ was selected as the material. The constitutive model of $\mathrm{Pb}$ is shown in Equation (1).

$$
\sigma=16.0 \varepsilon^{0.3}+6.9
$$

where, $\sigma$ is the equivalent stress whose unit is MPa and $\varepsilon$ is the equivalent strain.

The stress triaxiality is one of the most important parameters in the establishment of a void-closure model by many scholars. ${ }^{5,7,9,10}$ It is defined as the ratio of hydrostatic stress to equivalent stress. According to its definition, it can be considered that the stress triaxiality represents the relative magnitude of hydrostatic stress and equivalent stress. The Lode parameter was proposed for the study of the material yield criterion. ${ }^{19}$ The definition of the Lode parameter is $\left(2 \sigma_{2}-\sigma_{1}-\sigma_{3}\right) /\left(\sigma_{1}-\sigma_{3}\right)$. After an in-depth research by many scholars, it was found that the Lode parameter was also of great significance when describing the strain type. ${ }^{16}$ Moreover, it could represent the relative amounts of the principal values of the deviatoric stress tensor.

The stress tensor can be divided into the spherical stress tensor and deviatoric stress tensor. For a certain material, when the stress triaxiality and Lode parameter are determined, the main stress on the outer surface of the RVE model can be determined, and the stress state of the RVE model can be determined. ${ }^{20}$ In order to explore the influence of different stress states on the evolution law of a void, we studied the closure of a void under 25 groups of stress states, with stress triaxiality $T$ being -1 , $-0.67,-0.33,0,0.33$, and Lode parameter $\mu$ being -1 , $-0.5,0,0.5$, and 1 , respectively. Referring to Chbihi's method, the macroscopic stress state around the RVE model can be determined according to the Lode parameter and the stress triaxiality. ${ }^{20}$ These stress states basically cover the stress states corresponding to the common plastic deformation processes.

\section{RELATIONSHIP BETWEEN THE VOID CLOSURE AND STRESS STATES}

From practical experience and numerical-simulation results, it can be known that with the occurrence of deformation, the void shape changes from a sphere to an ellipsoid. ${ }^{20}$ Therefore, when the length of the short axis of a void is zero in the direction of compression, the void can be considered closed. Therefore, the initial diameter of the spherical void was defined as $d_{0}$. During deformation, the length of the short axis of the void in the $Z$ direction (the maximum-compression direction) was defined as $r_{Z}$, and the void shape coefficient in the $\mathrm{Z}$ direction was defined as $S_{Z}\left(S_{Z}=2 r_{Z} / d_{0}\right)$. When the shape coefficient in the $\mathrm{Z}$ direction is zero, the void is closed.

\subsection{Effect of the Lode parameter on the void-closure behavior}

According to the numerical-simulation results, the influence of the Lode parameter on the void closure can be obtained. Figure 3a shows the relationship between the void shape coefficient $S_{Z}$ and the macroscopic equivalent strain $E_{\mathrm{e}}$ when stress triaxiality $T$ is -0.33 and Lode pa-
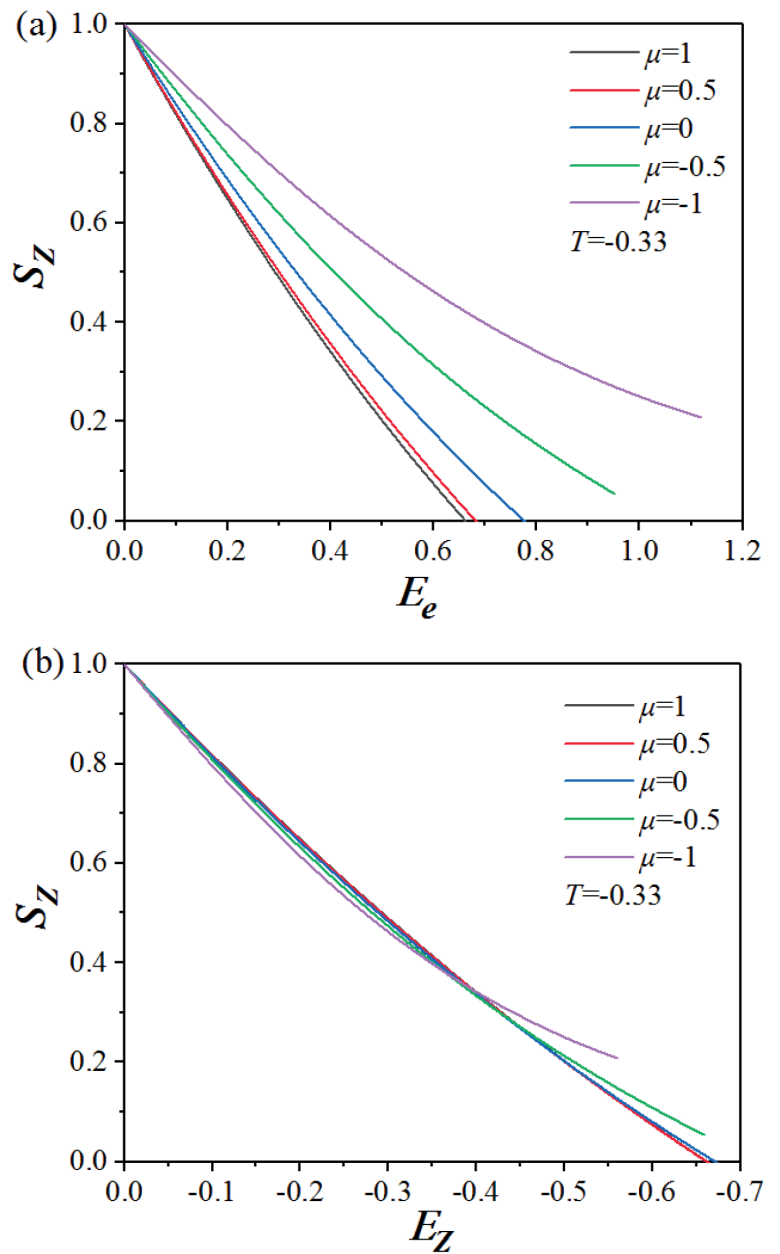

Figure 3: Relationship between $S_{Z}$ and $E_{\mathrm{e}} ; E_{\mathrm{Z}}$ under different Lode parameters: a) $S_{\mathrm{Z}}-E_{\mathrm{e}}$; b) $S_{\mathrm{Z}}-E_{\mathrm{Z}}$ 
rameter $\mu \in[-1,1]$. It can be seen on Figure 3a that when Lode parameter $\mu$ is 1 , the macroscopic equivalent strain $E_{\mathrm{e}}$ required for the void closure is minimal. When the equivalent strain $E_{\mathrm{e}}$ is constant, the larger the Lode parameter, the smaller is the void-shape coefficient $S_{Z}$. The same phenomenon occurs when stress triaxiality $T \in[-1,0.33]$. It is known that the larger the Lode parameter, the smaller is the macroscopic equivalent strain required for the void closure.

Figure $\mathbf{3 b}$ shows the relationship between the void-shape coefficient $S_{\mathrm{Z}}$ and the macroscopic compressive strain $E_{\mathrm{z}}$ when the stress triaxiality $T$ is -0.33 and the Lode parameter $\mu \in[-1,1]$. It can be seen on Figure 3b that when the compressive strain $E_{\mathrm{z}}$ is constant, the change in the Lode parameter has little influence on the change in the void-shape coefficient $S_{\mathrm{Z}}$. This effect is particularly evident when the Lode parameter $\mu \in[-0.5$, 1]. This is because the equivalent strain is the combined effect of the strains in the $X, Y$ and $Z$ directions, and it is numerically larger than the other three principal strains. The void-shape coefficient $S_{Z}$ represents the void-closure degree in the $Z$ direction, which has no direct relationship with the strains in the other two directions. It can be found that when the void-shape coefficient $S_{\mathrm{Z}}$ is selected
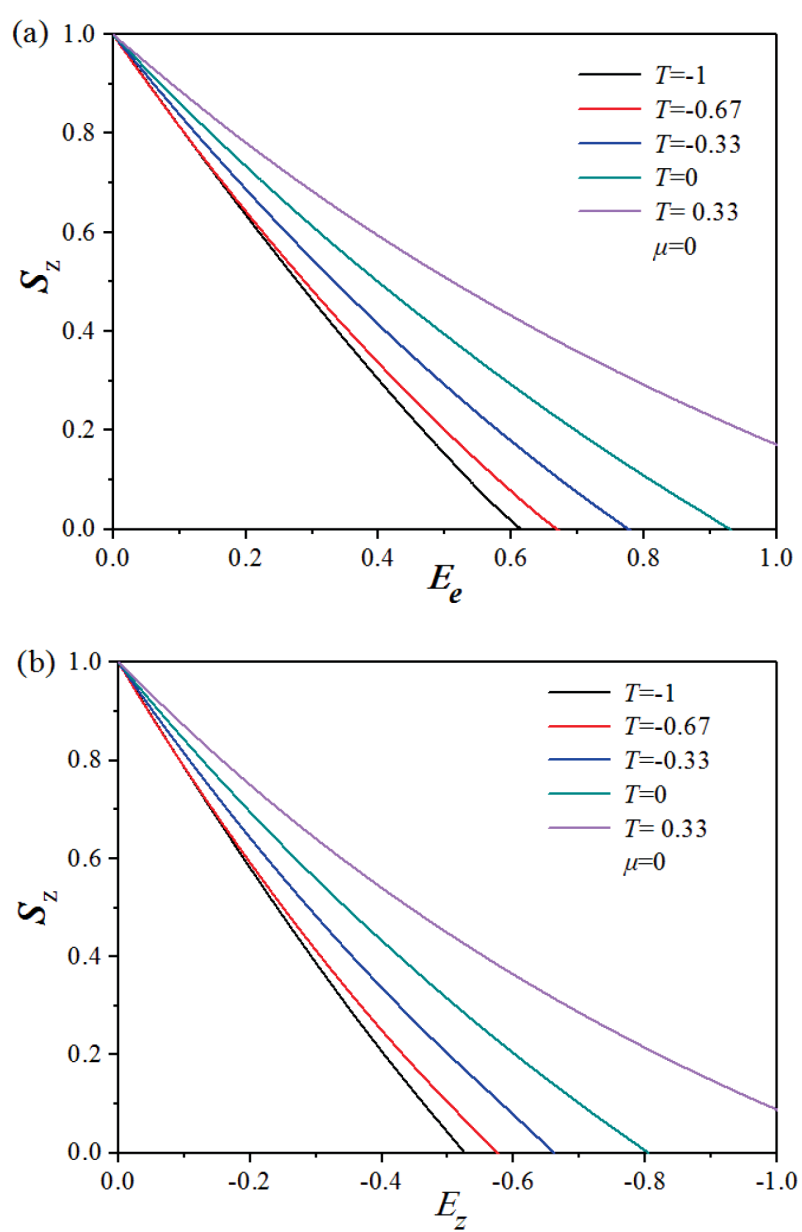

Figure 4: Relationship between $S_{\mathrm{Z}}$ and $E_{\mathrm{e}} ; E_{\mathrm{Z}}$ under different stresstriaxiality values: a) $S_{\mathrm{Z}}-E_{\mathrm{e}}$; b) $S_{\mathrm{Z}}-E_{\mathrm{Z}}$ to measure the void-closure degree, the maximum compressive strain $E_{\mathrm{z}}$ is more suitable as an independent variable than the equivalent strain $E_{\mathrm{e}}$.

\subsection{Effect of the stress triaxiality on the void-closure behavior}

Figure 4a shows the relationship between the void-shape coefficient $S_{\mathrm{Z}}$ and the macroscopic equivalent strain $E_{\mathrm{e}}$ when the Lode parameter is 0 and the stress triaxiality is different. As is shown in Figure 4a, the void-shape coefficient $S_{\mathrm{Z}}$ first decreases rapidly and then slowly with the increase in the macroscopic equivalent strain $E_{\mathrm{e}}$. When the macroscopic equivalent strain $E_{\mathrm{e}}$ is constant, the smaller the stress triaxiality, the smaller is the void-shape coefficient $S_{\mathrm{Z}}$. The void is most easily closed when the stress triaxiality $T$ is -1 . The same phenomenon occurs when the Lode parameter $\mu \in[-1,1]$. Figure $4 \mathbf{b}$ shows the relationship between the voidshape coefficient $S_{\mathrm{Z}}$ and the macroscopic compressive strain $E_{\mathrm{Z}}$ when the Lode parameter is 0 and the stress triaxiality is different. The rule from Figure $\mathbf{4 b}$ is consistent with that from Figure 4a.

In short, with a decrease in the stress triaxiality, the macroscopic equivalent strain required for a complete closure of a void decreases. That is, the greater the hydrostatic-pressure stress, the easier is the void closure.

\section{ESTABLISHMENT AND VERIFICATION OF THE NEW VOID-EVOLUTION MODEL}

Generally speaking, there are two methods for assessing the closure of a void. The first one uses the numerical-simulation software for measuring the void closure, setting a void into a workpiece, while the other method uses the void-closure criterion. The advantage of the first method is that the change in the voids in a workpiece can be observed visually. However, the disadvantage is that a simulation can only assess one or a few voids, and the mesh around the void needs to be partially refined. During the deformation process, the mesh distortion is serious, the mesh should be redivided many times and the simulation time is very long. The criterion method requires taking a certain void closure model as the criterion for predicting the void closure and assessing the void closure with a certain predicted value obtained with a calculation. The advantage of the criterion method is that there is no need to set a void into a workpiece. For a certain deformation process, the closure degree of a void at any position in the workpiece can be calculated using the void-evolution criterion. Moreover, the number of meshes and simulation time can be greatly reduced and the simulation period can be shortened.

Since there is a large number of randomly distributed voids in an ingot, the criterion method is undoubtedly one of the best methods for analyzing and assessing whether voids in different positions are closed in a forg- 
ing process. Based on the simulation results of the RVE model above, a new void-evolution model, taking into account all kinds of macroscopic stress states, is established. It is desirable to obtain a general method of studying the evolution of voids at arbitrary positions in an ingot.

\subsection{Establishment of the new void-evolution model}

As shown in Figures 3 and $\mathbf{4}$, when the stress triaxiality $T$ and Lode parameter $\mu$ are constant, the variation of the void-shape coefficient $S_{\mathrm{Z}}$ with the macroscopic compressive strain $E_{\mathrm{Z}}$ presents a conical relationship. According to the above analysis, when the stress triaxiality $T$ is constant and the Lode parameter is more than -0.5 , the influence of the Lode parameter on the void-shape coefficient $S_{\mathrm{Z}}$ is small. Based on this, the quadric equation shown as Equation (2) was used in this work to describe the relationships between the voidshape coefficient $S_{\mathrm{Z}}$, stress triaxiality $T$ and macroscopic compressive strain $E_{\mathrm{Z}}$.

$$
\begin{aligned}
& F\left(T, \mu, E_{z}\right)=1+a E_{z}^{2}+b E_{z}^{2}+c T E_{z}+ \\
& +d T E_{z}^{2}+e T^{2} E_{z}+f T^{2} E_{z}^{2}
\end{aligned}
$$

where $a, b, c, d, e$ and $f$ are the correlation coefficients.

When the Lode parameter is more than -0.5 , the influence of the Lode parameter on the void-shape coefficient $S_{\mathrm{Z}}$ is small. When the Lode parameter $\mu=0$, the correlation simulation data is selected for the modeling. Figure 5 shows the variation relation of the void-shape coefficient $S_{\mathrm{Z}}$ with stress triaxiality $T$ and macroscopic compressive strain $E_{\mathrm{z}}$ when the Lode parameter $\mu=0$. By fitting the data into Figure 5 with the custom function, Equation (3) can be obtained. The model can be applied to predict the evolution of the void-shape coefficient $S_{\mathrm{Z}}$ under a constant stress triaxiality.

$$
\begin{aligned}
& S_{z}\left(T, E_{z}\right)=1+1.57 E_{z}+0.51 E_{z}^{2}-0.89 T E_{z}- \\
& -0.34 T E_{z}^{2}-0.27 T^{2} E_{z}-0.12 T^{2} E_{z}^{2}
\end{aligned}
$$

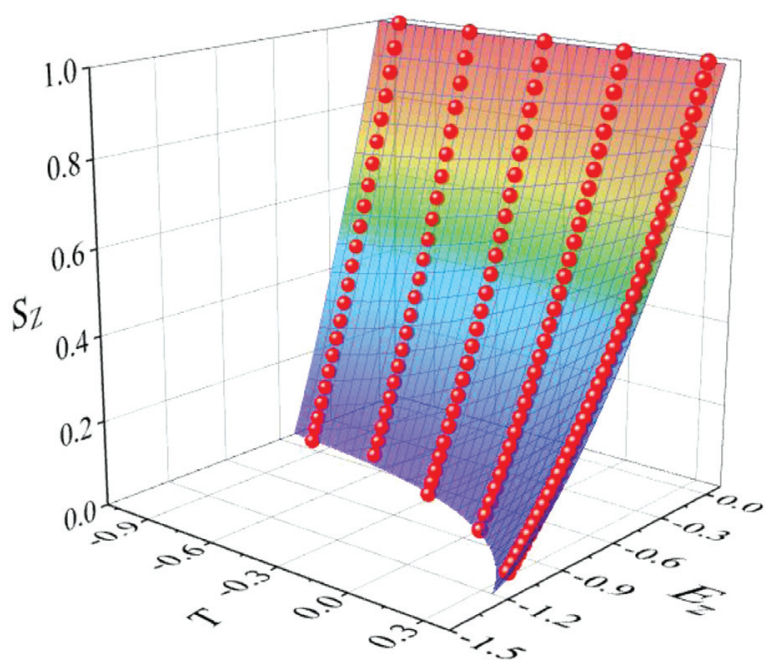

Figure 5: Relationships between $S_{\mathrm{Z}}, E_{\mathrm{Z}}$ and $T$ when $\mu=0$
To increase the universality of the model, we let Equation (3) take the partial derivative of $E_{\mathrm{Z}}$, and Equation (4) was obtained. It indicates the change rate of the void-shape coefficient $S_{\mathrm{Z}}$ when the compressive strain $E_{\mathrm{Z}}$ is constant and the stress triaxiality $T$ is varied.

$$
\begin{aligned}
& \frac{\partial S_{z}\left(T, E_{z}\right)}{\partial E_{z}}=1.57+1.02 E_{z}-0.89 T-0.68 T E_{z}- \\
& -0.27 T^{2} E_{z}-0.24 T^{2} E_{z}
\end{aligned}
$$

Based on the analysis above, the new void-closure model established in this paper is shown in Equation (5), which can be used to predict the evolution of the void-shape coefficient $S_{\mathrm{Z}}$ when the stress triaxiality $T$ changes with the deformation. In particular, when $E_{\mathrm{Z}}=0$, then $S_{Z}=1$, and this is the initial state of the void before deformation.

$$
\left\{\begin{array}{l}
\frac{\partial S_{z}\left(T, E_{z}\right)}{\partial E_{z}}=1.57+1.02 E_{z}-0.89 T-0.68 T E_{z}- \\
-0.27 T^{2}-0.24 T^{2} E_{z} \\
S_{z}=1+\int_{0}^{E_{z}} \frac{\partial S_{z}\left(T, E_{z}\right)}{\partial E_{z}} \mathrm{~d} E_{z}
\end{array}\right.
$$

\subsection{Comparison between the new void-evolution model and the previous models}

The establishment of a new model is important, but its accuracy is also one of the important factors of the model research. The new void-evolution model was compared with the previous models as follows.

\section{Models 1 and 2: the Gurson model and the G-T model}

The famous Gurson model is widely used in damage mechanics. ${ }^{15}$ According to this model, the porosity rate of change is:

$$
\mathrm{d} f=\frac{3 f(1-f) q_{1} \sinh \left(\frac{3 q_{2}}{2} T\right)}{2 \sqrt{1+q_{3} f^{2}-2 f q_{1} \cosh \left(\frac{3 q_{2}}{2} T\right)}} \mathrm{d} E_{\mathrm{e}}
$$

Besides, $f_{\mathrm{n}}=f_{\mathrm{n}-1}+\mathrm{d} f$. $f_{0}$ represents the initial porosity rate. When $f_{\mathrm{n}} / f_{0}$ approaches 0 , the void is closed. When $q_{1}=q_{2}=q_{3}=1$, Equation (6) is the result derived from the classical Gurson model. Later, Tvergaard and Needleman modified the model and they believed that when $q_{1}=1.5, q_{2}=1.0$ and $q_{3}=2.25$, the accuracy of the model is improved. ${ }^{21}$ Under this condition, Equation (6) is the well-known G-T model.

\section{Model 3: the BHS model}

Another famous model is the BHS model, which considers the effect of the Norton index of material on the void closure. ${ }^{22}$ This is shown in Equation (7): 
F. CHEN et al.: VOID-CLOSURE BEHAVIOR AND A NEW VOID-EVOLUTION MODEL FOR VARIOUS STRESS STATES

(a)

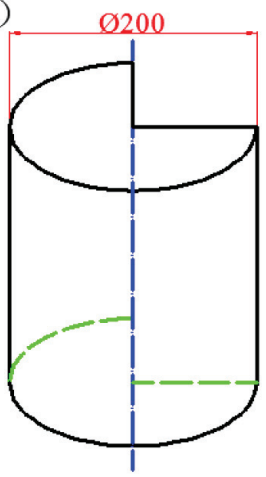

(b)

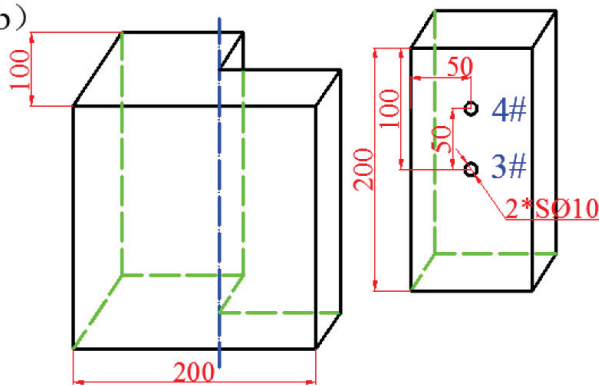

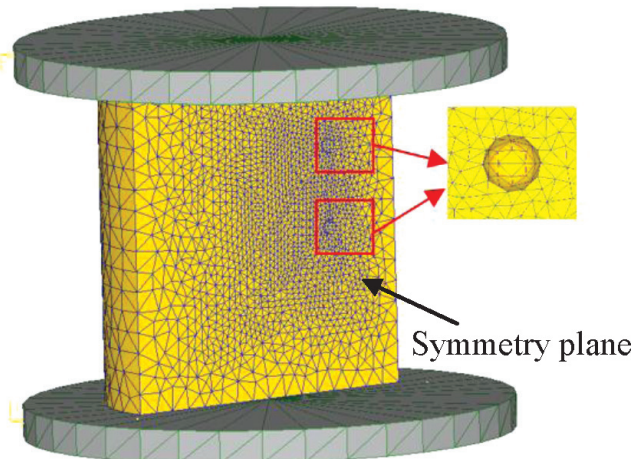

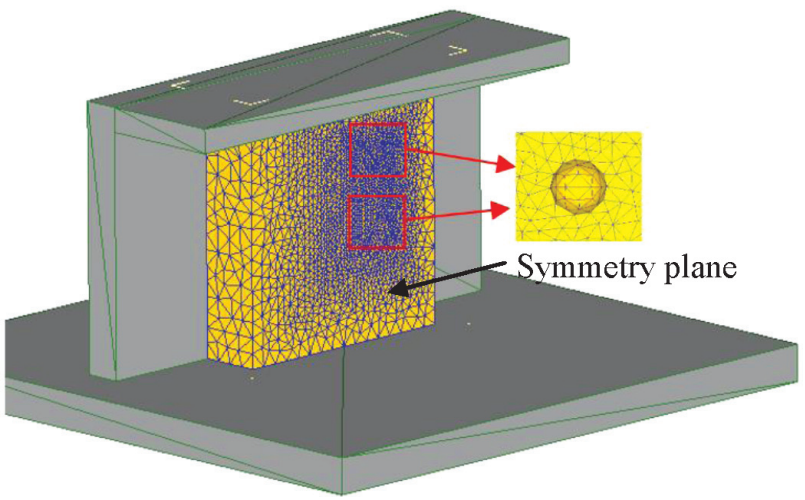

Figure 6: Geometric models for numerical simulation: a) upsetting, b) plane strain
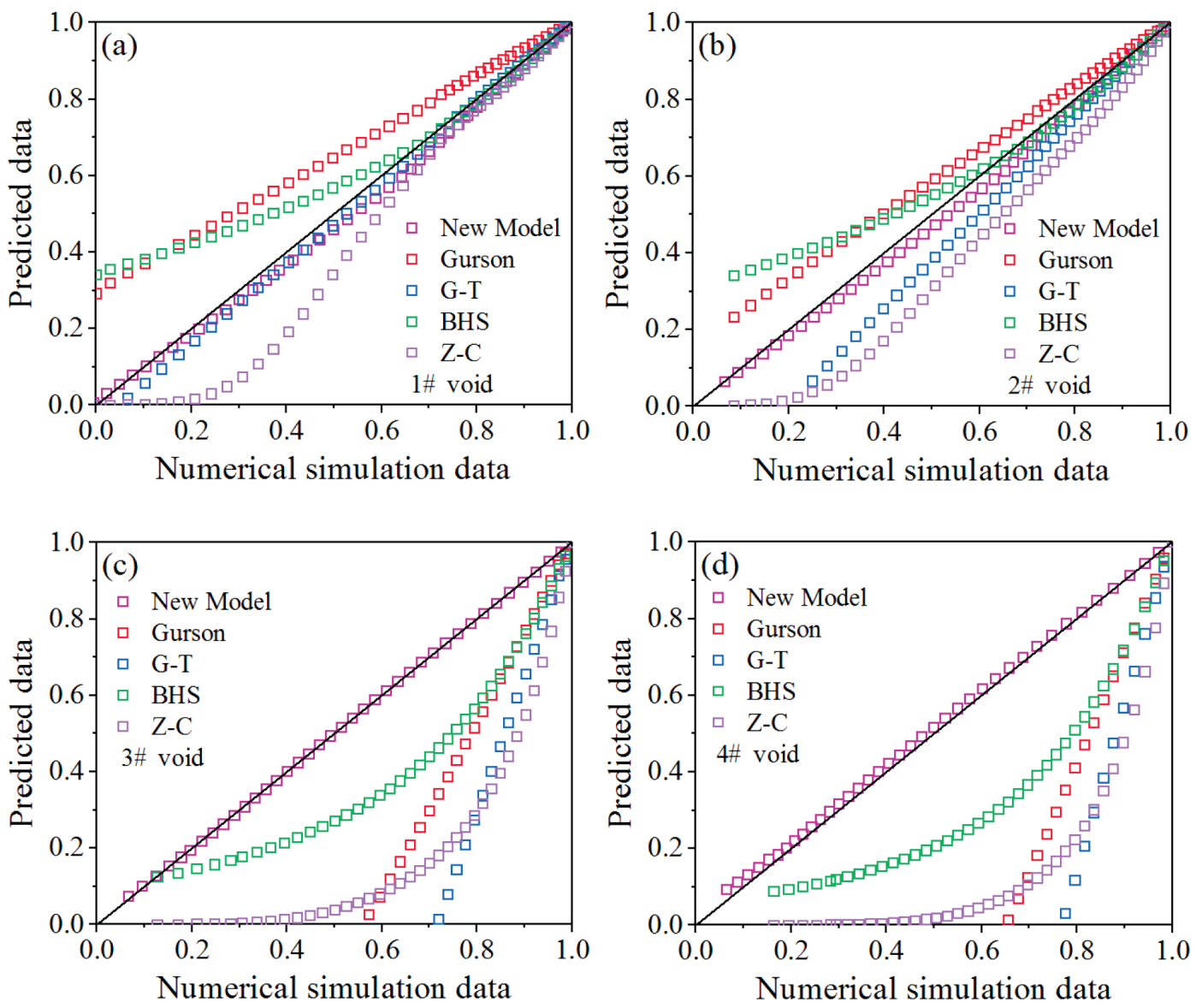

Figure 7: Comparison graph of calculation results 


$$
\ln \frac{V}{V_{0}}=\int_{0}^{E_{z}} \frac{3 s}{2}\left[\frac{3}{2 n}|T|+\frac{(n-1)(n+\omega(s))}{n^{2}}\right]^{n} d E_{\mathrm{e}}
$$

where $\mathrm{s}$ is the $\operatorname{sign}(T), T$ is the stress triaxiality, $\omega(1)=$ $\ln 3-2 / 3, \omega(-1)=2 \pi / 9 \sqrt{3}, \mathrm{n}$ is the Norton index of material.

\section{Model 4: the Z-C model}

Based on the mechanical analysis and numerical calculation, X. X. Zhang obtained an interpolation model of the void closure by studying the process of a spherical void evolving into an ellipsoid and, finally, closing into a gap. ${ }^{9}$ According to the numerical results of the model and void evolution, an evolution model of the void volume was proposed:

$$
\begin{aligned}
& \frac{V}{V_{0}}=\exp \left\{\operatorname { s i g n } ( \Sigma _ { \mathrm { m } } ) E _ { \mathrm { e } } \left[\frac{3}{2}\left(\frac{3}{2 n}|T|+\frac{(n-1)(5 n+2)}{5 n^{2}}\right)^{n}+\right.\right. \\
& \left.\left.+q_{1}|T|+q_{2} E_{e}^{2}+q_{3} E_{e}^{4}+q_{4}\right]\right\}
\end{aligned}
$$

Where $\Sigma_{\mathrm{m}}$ is the macroscopic hydrostatic stress, $T$ is the stress triaxiality, $n$ is the Norton index of material and $q_{1}, q_{2}, q_{3}, q_{4}$ are the coefficients associated with the Norton index of material.

In this part of the research, the void-evolution model obtained in the previous part was imported into finite-element software DEFORM-3D through secondary development, and two deformation processes including upsetting and plane deformation were simulated. $\mathrm{Pb}$ was also used in the simulation. The results of the void-evolution models obtained by the predecessors and the new void-evolution model were compared with those obtained with the traditional method of setting a void in a workpiece.

Geometric models for the numerical simulation of a set void in a workpiece are shown in Figure 6. The shear-friction coefficient between the workpiece and the anvils was set to 0.7 . The upset workpiece was a cylinder and the plane-strain workpiece was a cuboid. Based on the symmetry of the workpiece, the $1 / 2$ model of the workpiece was used in the numerical simulation.

By comparing the above four void-evolution models and the new void-evolution model established in this work, with the method of a set void in the workpiece, the final results were obtained as shown in Figure 7. The abscissa of Figure 7 represents the numerical-simulation results obtained with the method of a set void in the workpiece, while the ordinate indicates the calculation result for each model. The closer the data point is to the black line of slope 1 in the middle, the more accurate is the model. As shown in Figure 7, the calculation results for the new void-evolution model are the closest to the black line. Other models were built under axisymmetric stress, so errors of some models are relatively large. In particular, the error is the greatest when the void-closure degree is predicted under a plane-strain condition.

\subsection{Physical-simulation experiment design and model verification}

To further verify the accuracy of the new void-evolution model, an upsetting test of the cylindrical sample was carried out. Four different positions of voids were selected as shown in Figure 8a. Firstly, a $\phi 30 \times 30 \mathrm{~mm}$ cylindrical sample was processed along the axis to make a through-hole of $\phi 10 \mathrm{~mm}$. Secondly, a $\mathrm{Pb}$ sample was machined into a cylinder of $\phi 10 \times 30 \mathrm{~mm}$ using wire-electrode cutting. Thirdly, the cylinder was cut in half radially. Then, in each of its end, a $\phi 4 \mathrm{~mm}$ hemispherical void was made by milling. Finally, they were inserted into the through-hole of the larger cylinder to simulate the internal void of the ingot. The samples were processed and assembled as shown in Figure 8b. The processed cylinder samples were upset on a 100T hydraulic press and the deformation was about $(10,20,30$ and 40) $\%$, respectively. The deformed cylinders were cut along the central axis with wire-electrode cutting. The sections of the samples were highlighted with blue chalk. Parts of the samples after the cutting are shown in Figure 9. By measuring the size of the voids with physical-simulation experiments, the closure degrees of the voids in these four samples under different deformation quantities could be obtained.

A cylinder of the same size as the physical-simulation sample without a void was used as the geometric model of the numerical simulation. The upsetting process of the $\mathrm{Pb}$ sample was numerically simulated using
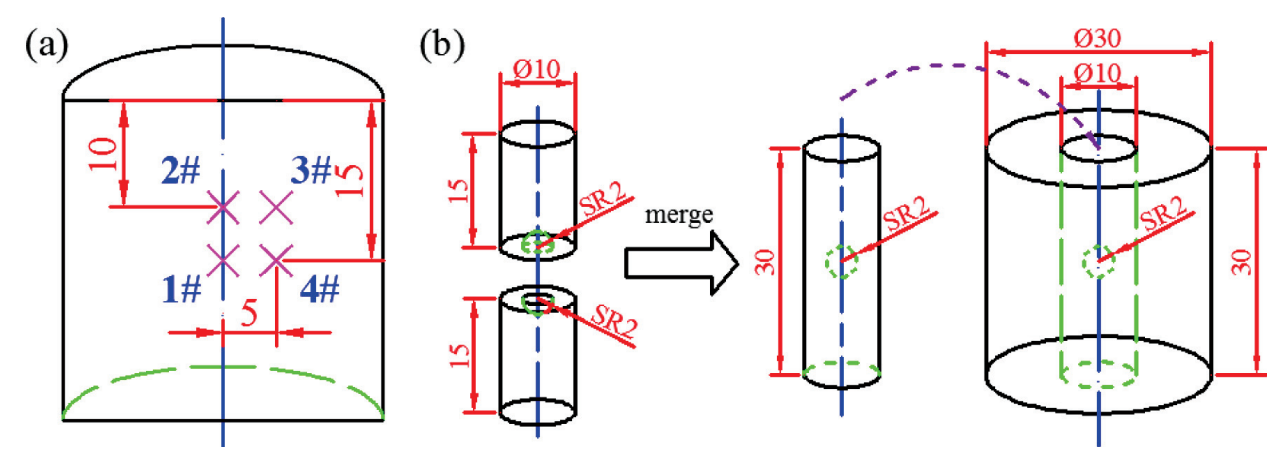

Figure 8: Schematic diagram of a physical-simulation sample: a) schematic diagram of the locations of the voids, b) assembly method for the sample with void $1 \#$ 

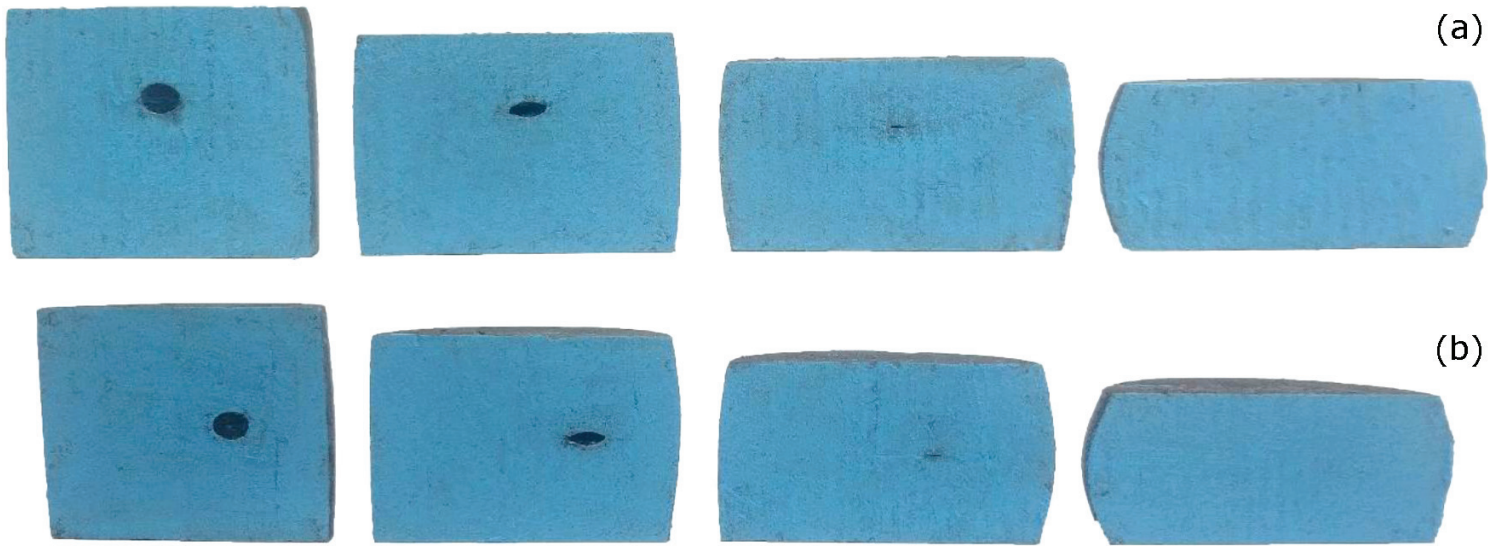

(b)

Figure 9: Physical-simulation results of upsetting test: a) samples with void 2\#, b) samples with void 4\#

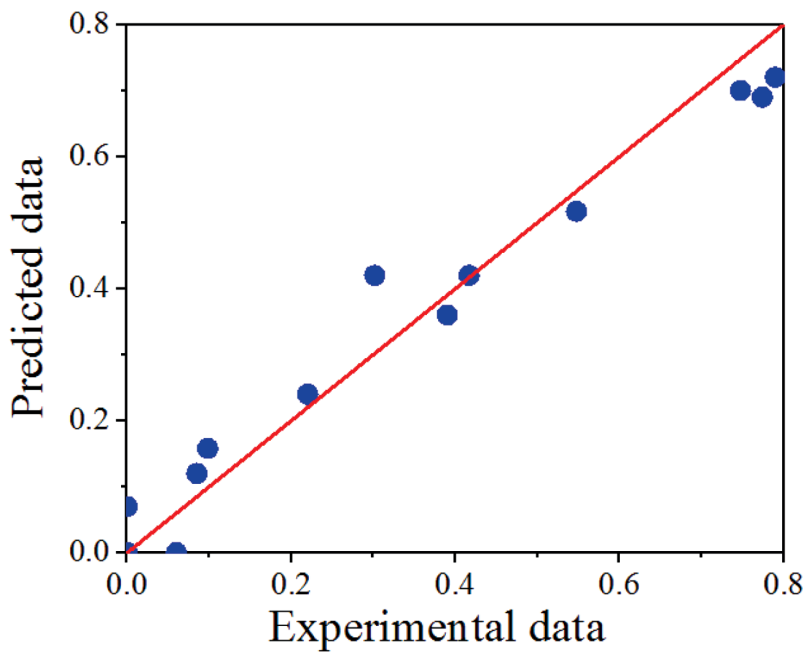

Figure 10: Comparison of the results of the physical-simulation experiments and the new model

the new model. The results of the physical-simulation experiments and the new model were obtained as shown in Figure 10. In order to verify the reliability of the criterion, the root mean square error (RMSE) was calculated in accordance with the following formula.

$$
R M S E=\sqrt{\frac{1}{n} \sum_{i=1}^{n}\left(S_{\mathrm{e}}-S_{\mathrm{p}}\right)^{2}}
$$

where $S_{\mathrm{e}}$ is the experimental data, $S_{\mathrm{p}}$ is the predicted data and $n$ is the total number of data points. The results show that the RMSE error is 0.05 . It is clear that the calculation results for the new void-evolution model are in good agreement with the experimental results, verifying the accuracy of the new model.

In conclusion, the numerical simulation and experimental results show that the new void-evolution model is mainly applicable to predict the closure degree of voids at different positions in an ingot during plastic deformation. The void-evolution model can be used to predict the void closure irrespective of whether the ingot undergoes compressive deformation (such as upsetting) or plane deformation (such as plane strain and rolling).

\section{CONCLUSIONS}

Based on the RVE model, a comprehensive theoretical analysis and numerical simulation, the influence of the Lode parameter and stress triaxiality on the void closure is expounded. In addition, according to the above research, a new void-evolution model considering various macroscopic stress states is proposed, and the following main conclusions are obtained:

1) The Lode parameter and stress triaxiality have important effects on the void closure. The larger the Lode parameter, the smaller is the equivalent strain required for the void closure. When the Lode parameter $\mu \in[0,1]$, the difference in the macroscopic compressive strain required for the void closure is minimal. The smaller the stress triaxiality, the smaller are the macroscopic equivalent strain and the macroscopic compressive strain required for a complete closure of a void.

2) When the void-shape coefficient in the direction of the maximum compressive strain is used to describe the closure degree of a void, the macroscopic compressive strain is more suitable as an independent variable than the macroscopic equivalent strain. Based on this, a new void-evolution model is established, whose accuracy is close to the numerical-simulation result for a set void in a workpiece. The model can predict the void closure under various stress states with high accuracy.

3) The root mean square error (RMSE) of the new void-evolution model is 0.05 when compared with the physical-simulation results. The accuracy of the new model is verified. Using this model, the process design and optimization of ingot casting can be carried out conveniently, and the evolution of voids at any position in an ingot can be assessed effectively.

\section{Acknowledgment}

The work was financially sponsored by the National Natural Science Foundation of China (No.51575372), the Start-Up Fund for Scientific Research of the Taiyuan University of Science and Technology (No.20172011) 
and the Shanghai Research Center of Engineering Technology for Large Parts Thermal Manufacturing.

\section{REFERENCES}

${ }^{1}$ F. Faini, A. Attanasio, E. Ceretti, Experimental and FE analysis of void closure in hot rolling of stainless steel, J. Mater. Process. Tech., 259 (2018), 235-242, doi:10.1016/j.jmatprotec.2018.04.033

${ }^{2}$ H. G. Huang, Y. Liu, F. S. Du, Void Closure Behavior in Large Diameter Steel Rod during H-V Rolling Process, J. Iron Steel Res. Int., 21 (2014) 3, 287-294, doi:10.1016/S1006-706X(14)60044-3

${ }^{3}$ L. Yuan, J. Xiong, Y. Peng, Modeling void closure in solid-state diffusion bonding of TC4 alloy, Vacuum, 173 (2020), 109-120, doi:10.1016/j.vacuum.2019.109120

${ }^{4}$ P. Hibbe, G. Hirt, Analysis of the bond strength of voids closed by open-die forging, Int. J. Mater. Form., 13 (2019), 117-126, doi:10.1007/s12289-019-01474-7

${ }^{5}$ M. Tanaka, S. Ono, M. Tsuneno, Factors contributing to crushing of voids during forging, J. Jpn. Soci. Technol. Plast., 306 (1986) 27, 852-859, doi:not found

${ }^{6}$ M. Tanaka, S. Ono, M. Tsuneno, A numerical analysis on void crushing during side compression of round bar by flat dies, J. Jpn. Soci. Technol. Plast., 314 (1987) 28, 238-244

${ }^{7}$ R. S. Nalawade, P. P. Patil, G. Balachandran, Void Closure in a Large Cross Section Bars Hot Rolled from a Low Alloy Steel Ingot Casting, T. Indian I. Metals, 69 (2016) 9, 1711-1721, doi:10.1007/ s12666-016-0831-x

${ }^{8}$ K. Chen, Y. Yang, G. Shao, Strain function analysis method for void closure in the forging process of the large-sized steel ingot, Comp. Mater. Sci., 51 (2012) 1, 72-77, doi:10.1016/j.commatsci. 2011.07.011

${ }^{9}$ X. X. Zhang, Z. S. Cui, W. Chen, A criterion for void closure in large ingots during hot forging, J. Mater. Process. Tech., 209 (2009) 4, 1950-1959, doi:10.1016/j.jmatprotec.2008.04.051

${ }^{10}$ N. Harris, D. Shahriari, M. Jahazi, Development of a fast converging material specific void closure model during ingot forging, J. Manuf. Process., 26 (2017), 131-141, doi:10.1016/j.jmapro.2017.02.021

${ }^{11}$ Tian Duanyang, Shu Xuedao, Zhu Ying, et al. Closure laws of void in the core of cross wedge rolling shaft based on the floating-pressure method, Int. J. Adv. Manuf. Tech., 98 (2018) 9-12, 2905-2916, doi:10.1007/s00170-018-2448-1
${ }^{12}$ J. J. Park, Numerical analysis of void closure in metal forming, Pro Manuf., 15 (2018), 1841-1846, doi:10.1016/j.promfg.2018.07.206

${ }^{13}$ S. H. Zhang, X. R. Jiang, Z. X. Xia, Mathematical modeling of closure behavior for a centrally elliptical void in thick slab, Mech. Mater., 145 (2020), 1-11, doi:10.1016/j.mechmat.2020.103373

${ }^{14}$ L. Zhang, W. F. Shen, C. Zhang, Numerical simulation of different types of voids closure in large continuous casting billet during multi-pass stretching process, Pro. Eng., 207 (2017), 532-537, doi:10.1016/j.proeng.2017.10.817

${ }^{15}$ A. L. Gurson, Continuum Theory of Ductile Rupture by Void Nucleation and Growth: Part I - Yield Criteria and Flow Rules for Porous Ductile Media, J. Eng. Technol., 99 (1977), 2-15, doi:10.1115/ 1.3443401

${ }^{16}$ Y. Zhu, M. D. Engelhardt, K. Ravi, Combined effects of triaxiality, Lode parameter and shear stress on void growth and coalescence, Eng. Fract. Mech., 199 (2018), 410-437, doi:10.1016/j.engfracmech. 2018.06.008

${ }^{17}$ L. E. Dæhli, D. Morin, T. Børvik, A Lode-dependent Gurson model motivated by unit cell analyses, Eng. Fract. Mech., 190 (2017) 1, 299-318, doi:10.1016/j.engfracmech.2017.12.023

${ }^{18}$ I. Barsoum, J. Faleskog, Micromechanical analysis on the influence of the Lode parameter on void growth and coalescence, Int. J. Solids Struct., 48 (2011) 6, 925-938, doi:10.1016/j.ijsolstr.2010.11.028

${ }^{19}$ W. Lode, Versuche über den Einfluß der mittleren Hauptspannung auf das Fließen der Metalle Eisen, Kupfer und Nickel, Zeitschrift Für Physik A Hadrons \& Nuclei, 36 (1926) 11, 913-939, doi:10.1007/ BF01400222

${ }^{20}$ A. Chbihi, P. O. Bouchard, M. Bernacki, Influence of Lode angle on modelling of void closure in hot metal forming processes, Finite Elem. Anal. Des., 126 (2017), 13-25, doi:10.1016/j.finel.2016. 11.008

${ }^{21} \mathrm{~V}$. Tvergaard, A. Needleman, Analysis of the cup-cone fracture in a round tensile bar, Acta Metall., 32 (1984), 157-69, doi:10.1016/ 0001-6160(84)90213-X

${ }^{22}$ B. Budiansky, J. W. Hutchinson, S. Slutsky, Void growth and collapse in viscous solids, Mechanics of Solids, The Rodney Hill $60^{\text {th }}$ Anniversary Volume, (1982), 13-45, doi:10.1016/B978-0-08025443-2.50009-4 